\title{
WEIGHTED REGULARITY ESTIMATES IN ORLICZ SPACES FOR THE PARABOLIC SCHRÖDINGER OPERATORS
}

\author{
FENGPING YAO
}

Abstract. In this paper we study regularity estimates in weighted Orlicz spaces for the parabolic Schrödinger operator

$$
P=\frac{\partial}{\partial t}-\Delta+V(x, t)
$$

with non-negative potentials $V(x, t)$ satisfying certain reverse Hölder class. As a corollary we obtain the classical $L^{p}$-type regularity estimates for such operator.

Mathematics subject classification (2010): 35K10, 46E30.

Keywords and phrases: Weighted, regularity, Orlicz spaces, parabolic, Schrödinger operator.

\section{REFERENCES}

[1] E. Acerbi And G. Mingione, Gradient estimates for a class of parabolic systems, Duke Math. J., 136, (2007), 285-320.

[2] E. Acerbi And G. Mingione, Gradient estimates for the $p(x)$-Laplacean system, J. Reine Angew. Math., 584, (2005), 117-148.

[3] R. A. Adams And J. J. F. Fournier, Sobolev spaces (2nd edition), Academic Press, New York, 2003.

[4] A. Benkirane And A. Elmahi, An existence theorem for a strongly nonlinear elliptic problem in Orlicz spaces, Nonlinear Anal., 36, (1999), 11-24.

[5] M. Bramanti, L. Brandolini, E. Harboure and B. Viviani, Global $W^{2, p}$ estimates for nondivergence elliptic operators with potentials satisfying a reverse Hölder condition, Ann. Mat. Pura Appl. (4), 191, (2) (2012), 339-362.

[6] V. BÖGELEIN AND F. DUZAAR, Higher integrability for parabolic systems with non-standard growth and degenerate diffusions, Publ. Mat., 55, (1) (2011), 201-250.

[7] V. Bögelein, F. DuZaAR And G. Mingione, The regularity of general parabolic systems with degenerate diffusion, Mem. Amer. Math. Soc., 221, (1041) (2013), vi+143 pp.

[8] S. BYUn, Dian K. Palagachev And S. RYU, Weighted $W^{1, p}$ estimates for solutions of nonlinear parabolic equations over non-smooth domains, Bulletin of London Mathematical Society, 45, (4) (2013), 765-778.

[9] S. Byun, J. OK, D. K. Palagachev and L. G. Softova, Parabolic systems with measurable coefficients in weighted Orlicz spaces, Commun. Contemp. Math., in press.

[10] S. BYUN AND S. RYU, Global weighted estimates for the gradient of solutions to nonlinear elliptic equations, Ann. Inst. H. Poincaré Anal. Non Linéaire, 30, (2) (2013), 291-313.

[11] L. A. Caffarelli And I. Peral, On $W^{1, p}$ estimates for elliptic equations in divergence form, Comm. Pure Appl. Math., 51, (1998), 1-21.

[12] A. P. CALDERón AND A. ZYGmund, On the existence of certain singular integrals, Acta Math., 88, (1952), 85-139.

[13] A. Carbonaro, G. Metafune and C. Spina, Parabolic Schrödinger operators, J. Math. Anal. Appl., 343, (2) (2008), 965-974.

[14] T. Donaldson, Nonlinear elliptic boundary-value problems in Orlicz-Sobolev spaces, J. Diff. Eq., 10, (1971), 507-528. 
[15] T. Donaldson, Inhomogeneous Orlicz-Sobolev spaces and nonlinear parabolic initial value problems, J. Diff. Eq., 16, (1974), 201-256.

[16] L. Evans, Partial differential equations, Graduate Studies in Mathematics, 19. American Mathematical Society, Providence, RI, 1998.

[17] A. Fiorenza And M. Krbec, Indices of Orlicz spaces and some applications, Comment. Math. Univ. Carolin., 38, (3) (1997), 433-451.

[18] W. GAO AND Y. JiAng, $L^{p}$ estimate for parabolic Schrödinger operator with certain potentials, J. Math. Anal. Appl., 310, (1) (2005), 128-143.

[19] R. Haller-Dintelmann, H. Heck And M. Hieber, $L^{p}-L^{q}$ estimates for parabolic systems in non-divergence form with VMO coefficients, J. London Math. Soc. (2), 74, (3) (2006), 717-736.

[20] J. Jiménez URREA, The Cauchy problem associated to the Benjamin equation in weighted Sobolev spaces, J. Differential Equations, 254, (4) (2013), 1863-1892.

[21] R. A. Kerman AND A. TORChinsky, Integral inequalities with weights for the Hardy maximal function, Studia Math., 71, (1982), 277-284.

[22] V. KokilashVili AND M. KRBEC, Weighted Inequalities in Lorentz and Orlicz Spaces, World Scientific, 1991.

[23] A. Kufner, Weighted Sobolev spaces, Translated from the Czech. A Wiley-Interscience Publication. John Wiley and Sons, Inc., New York, 1985.

[24] T. KuUsi And G. Mingione, Universal potential estimates, J. Funct. Anal., 262, (2012), 4205-4269.

[25] D. LI AND L. WANG, A new proof for the estimates of Calderón-Zygmund type singular integrals, Arch. Math. (Basel), 87, (5) (2006), 458-467.

[26] G. M. Lieberman, Second order parabolic differential equations, World Scientific Publishing Co., Inc., River Edge, NJ, 1996.

[27] T. Mengesha And N. Phuc, Weighted and regularity estimates for nonlinear equations on Reifenberg flat domains, J. Differential Equations, 250, (5) (2011), 2485-2507.

[28] T. Mengesha And N. Phuc, Global estimates for quasilinear elliptic equations on Reifenberg flat domains, Arch. Ration. Mech. Anal., 203, (1) (2012), 189-216.

[29] G. Mingione, The Calderón-Zygmund theory for elliptic problems with measure data, Ann. Sc. Norm. Super. Pisa Cl. Sci. (5), 6, (2) (2007), 195-261.

[30] B. MucKenhoupt, Weighted norm inequalities for the Hardy maximal function, Trans. Amer. Math. Soc., 165, (1972), 207-226.

[31] W. ORLICZ, Üeber eine gewisse Klasse von Räumen vom Typus B, Bull. Int. Acad. Pol. Ser. A, 8, (1932), 207-220.

[32] M. RaO AND Z. Ren, Applications of Orlicz spaces, Marcel Dekker Inc., New York, 2000.

[33] Z. SHEN, On the Neumann problem for Schrödinger operators in Lipschitz domains, Indiana Univ. Math. J., 43, (1) (1994), 143-176.

[34] Z. SHEN, $L^{p}$ estimates for Schrödinger operators with certain potentials, Ann. Inst. Fourier (Grenoble), 45, (2) (1995), 513-546.

[35] E. M. Stein, Harmonic Analysis, Princeton Univareity Press, Princeton, 1993.

[36] A. Torchinsky, Real-Variable Methods in Harmonic Analysis, Pure Appl. Math., vol. 123, Academic Press, Inc., Orlando, FL, 1986.

[37] L. Wang, F. YaO, S. Zhou And H. Jia, Optimal regularity for the Poisson equation, Proc. Amer. Math. Soc., 137, (2009), 2037-2047.

[38] K. ZHANG, Regularity in Orlicz spaces for nondivergence elliptic operators with potentials satisfying a reverse Hölder condition, Electron. J. Qual. Theory Differ. Equ., 78, (2013), 1-16. 